\title{
A Novel Rehabilitation Program Using Neuromuscular Electrical Stimulation (NMES) and Taping for Shoulder Pain in Swimmers: A Protocol and Case Example
}

\author{
Noah Smith, PT, DPT, MPH ${ }^{1}$, Rachel Hotze, PT, DPT ${ }^{2}$, Angela R Tate, PT, $\mathrm{PhD}^{3}$ \\ ${ }^{1}$ Drayer Physical Therapy Institute, ${ }^{2}$ Therapy Solutions LLC, ${ }^{3}$ Excel Physical Therapy; Arcadia University \\ Keywords: neuromuscular electric stimulation (nmes), scapula, shoulder, swimmers, taping \\ https://doi.org/10.26603/001c.21234
}

\section{International Journal of Sports Physical Therapy}

Vol. 16, Issue 2, 2021

\begin{abstract}
In-pool return to swim protocols have been described for swimmers returning from being deactivated from swimming due to a shoulder injury who have full shoulder strength. Many swimmers actively participate in swim practice and competition with shoulder pain and experience deficits in performance. There are multiple reported risk factors associated with shoulder pain among swimmers, including training errors and physical impairments. These include pool and dry-land training errors, weakness in the scapular stabilizers and rotator cuff, and muscle tightness. A need exists for dry-land rehabilitation programs for impairments common to swimmers that can be performed in a traditional outpatient physical therapy setting. The purpose of this clinical commentary is to present a protocol using neuromuscular electrical stimulation (NMES), taping, strengthening, and stretching to address impairments that are common among swimmers while allowing continued active participation in practice and competition.
\end{abstract}

\section{Level of Evidence}

Level 5

\section{BACKGROUND AND PURPOSE}

Given the high shoulder injury rates of competitive swimmers, return to swim protocols (RTSP) can provide guidance to coaches and those involved in the rehabilitation of these athletes. Two RTSP have been previously described. Both provide excellent guidelines for training progressions based on shoulder symptoms during and after a workout. 1,2 Hamman's ${ }^{1}$ protocol provides guidance for swimmers who have been deactivated from swimming for more than six weeks and less than six weeks. This program is structured using a unique graded loading scheme of distance and interval time-based training. This system permits individualization of training based on a swimmers' current training speed but requires that the swimmer be able to perform individual intervals during their practice. This may not be feasible if the swimmer has multiple teammates per lane training on uniform time intervals. Spigelman et $\mathrm{al}^{2}$ provide an overview of swimming terminology, tools, drills, as well as a swimming volume and training-based RTSP which incorporates gradual loading of the shoulder. However, the criteria for beginning the RTSP require the shoulder to be nearly pain-free and the strength of scapular and glenohumeral muscles to be $5 / 5$. Initiating this RTSP proves challenging given that competitive swimmers seeking care often present with substantial shoulder pain and impairments such as trapezius weakness. ${ }^{3}$ These factors disqualify an individual from beginning this protocol and clinicians are left without guidance on progressing this group of patients to meet the criteria required to begin the RTSP safely. Additionally, the protocol from Spigelman et $\mathrm{al}^{2}$ appears to be intended for swimmers who have undergone surgery or have been unable to train, as was the protocol described by Hamman. ${ }^{1}$

Swimmers generally have less than optimal surgical outcomes for persistent shoulder pain associated with laxity, labral pathology and subacromial impingement. Montgomery et al reported that only $20 \%$ of swimmers returned to pre-surgery training volume after arthroscopic capsular plication and Brushoj et al found that only 56\% of swimmers competed at their pre-injury level after shoulder surgeries that included debridement, bursectomies and partial coraco-acromial ligament releases. ${ }^{4,5}$ Therefore, conservative management is preferred whenever possible. Many competitive swimmers that seek care for shoulder pain are currently having difficulty managing their training and re-

\footnotetext{
a Corresponding Author:

Noah Smith, PT, DPT, MPH

Email:ncsmith712@gmail.com
} 
Table 1: Identification and Management of risk factors

\begin{tabular}{|c|c|}
\hline Training Errors & Modification/Intervention if Present \\
\hline $\begin{array}{l}\text { High swimming volume: Sein et al } \\
\text { reported a 4-fold increase in } \\
\text { shoulder tendinopathy in those } \\
\text { swimming }>35,000 \mathrm{~m} / \text { week so we } \\
\text { consider }>35,000 \text { as high swimming } \\
\text { volume } 12\end{array}$ & $\begin{array}{l}\text { Low irritability: Perform other indicated modifications for } 2-3 \text { weeks without reduction in } \\
\text { swimming volume and reassess } \\
\text { High irritability: Use of long blade swim fins for most of practice ( } 50-75 \%) \text {. If pain is } \\
\text { constant, reduce swimming volume by } 25 \%-50 \% \text {. Consider total rest from swimming for a } \\
\text { period if symptoms remain irritable. Begin increasing swimming volume again by no more } \\
\text { than } 10 \% \text { weekly, }{ }^{14} \text { beginning with freestyle and adding other strokes as needed. Follow } \\
\text { soreness rules for progressions outlined by Spigelman et al }{ }^{2}\end{array}$ \\
\hline Lack of cross training ${ }^{3}$ & Incorporate dry land aerobic and lower extremity/core strengthening 9,15 \\
\hline $\begin{array}{l}\text { Kicking drills with use of kickboard } \\
\text { overhead or streamline position in } \\
\text { swimmer with shoulder pain } 6,8\end{array}$ & $\begin{array}{l}\text { No overhead kickboard use and no streamline kicking - use kick pull drills or backstroke } \\
\text { kicking with arms at side or kickboard held across chest instead }\end{array}$ \\
\hline $\begin{array}{l}\text { Lack of specific dry land training or } \\
\text { participation in a program involving } \\
\text { repetitive overhead lifting (such as } \\
\text { kettlebells) or lacking posterior } \\
\text { shoulder/scapular/core } \\
\text { strengthening7 }\end{array}$ & $\begin{array}{l}\text { Implement dry land program addressing swimmer's mobility restrictions and typical } \\
\text { weaknesses in the scapular, posterior shoulder, and core muscles }\end{array}$ \\
\hline $\begin{array}{l}\text { Stroke errors such as increased } \\
\text { shoulder internal rotation or } \\
\text { crossing midline at hand entry } 11\end{array}$ & Refer to stroke specialist/swim coach \\
\hline
\end{tabular}

port limitations in performance as well as activities of daily living. 3,6 Therefore, a need exists for management of swimmers who are currently training with shoulder pain. Those with low to moderate pain that occurs only during and/ or after swimming can usually be effectively managed with modifications to their swimming program and an accompanying comprehensive rehabilitation program. For swimmers with pain at rest and/or severe pain with normal ADLs such as grooming hair and carrying a backpack, a medical workup including imaging and removal from swimming participation are likely indicated. A rehabilitation program can then be implemented with gradual progression to inwater training. The purpose of this clinical commentary is to present a protocol using neuromuscular electrical stimulation (NMES), taping, strengthening, and stretching to address impairments that are common among swimmers while allowing continued active participation in practice and competition. This commentary will conclude with a case example describing the use of these guidelines for a competitive high school swimmer.

\section{EXAMINATION AND IDENTIFICATION OF RISK FACTORS}

Evaluation of a swimmer with shoulder pain includes a comprehensive history of the injury and identification of potential risk factors in the swimmers' training. Several training errors among swimmers have been reported in the literature including: excessive swimming volume, lack of cross training, utilization of kicking drills that exacerbate shoulder symptoms, lack of a swimmer specific dryland program, and biomechanical errors in the swimming stroke. ${ }^{3,6-12}$ Table 1 describes these commonly reported training errors and modifications that can be implemented to reduce the adverse effects of these errors. Interventions should be chosen based on symptom irritability for which a classification system has been described extensively elsewhere by McClure et al. ${ }^{13}$ For competitive swimmers, this commentary will use high and low irritability classifications. History and exam findings in a swimmer with high irritability include pain $\geq 4 / 10$ with swimming and pain with activities of daily living (ADL) and/or at rest. Interventions for these patients will initially focus on minimizing physical stress, activity modification, and addressing impairments in non-provocative positions. These patients may initially require rest from swimming if symptoms are constant and/or are of high intensity. A low irritability classification is used when pain is $\leq 3 / 10$ with swimming, pain is minimal $(\leq 2 /$ 10 ) with ADLs, and the patient is pain-free at rest. In these cases, interventions will address impairments and be designed to return swimmers to high functional demand.

Depending on irritability of a patient's presentation, swimming volume, dryland program, cross training, and drills can be modified to appropriately reduce load on the painful shoulder(s) and address impairments contributing to the patient's shoulder pain. Relevant impairments can be identified through a comprehensive physical shoulder evaluation. A thorough screening of the cervical spine is necessary, as swimmers frequently have a relevant cervical component to their shoulder pain and may benefit from use of a swimmers' snorkel to reduce repetitive cervical rotation. An exam should also include evaluation of posture to identify any non-optimal postures including forward head or protracted scapula. Range of motion and muscle length assessments should include glenohumeral active and passive ranges of motion, pectoralis minor length, and latissimus dorsi length in addition to examination for posterior shoulder tightness using the Myers test. ${ }^{16}$ It is recommended that clinicians assess strength of the rotator cuff and scapular muscles with a handheld dynamometer which has good to excellent intra- and inter-rater reliability, ${ }^{17}$ has been found 
to be sensitive to detecting muscle strength changes over time, ${ }^{18}$ and provides valid and reliable assessment of strength when compared to the gold standard for muscle force testing, isokinetic dynamometry. ${ }^{19}$ Posterior shoulder endurance can be assessed with the posterior shoulder endurance test, ${ }^{20}$ and core endurance through various measures described in the literature such as the Sorenson test for lumbar extension, ${ }^{21}$ the unilateral hip bridge endurance test, ${ }^{22}$ the prone plank test, ${ }^{23}$ and variations of the isometric side plank. ${ }^{24}$ Shoulder special testing for subacromial pain syndrome include the Neer's test, Hawkins Kennedy test, presence of a painful arc, and the Jobe empty can test. Clinicians may use the scapula reposition test ${ }^{25}$ and modified scapular assistance test ${ }^{26}$ as well as strength assessment of the middle and lower trapezius and serratus anterior to identify swimmers with scapular dysfunction. Table $\underline{2}$ presents the use of handheld dynamometry for muscle strength testing as well as several special tests for core and shoulder endurance and flexibility.

\section{INTERVENTIONS TO ADDRESS IDENTIFIED IMPAIRMENTS}

A staged rehabilitation approach can be utilized to address the impairments found on the examination. The authors' approach will be described for typical impairments seen among injured swimmers who continue to participate in full or modified swim practices throughout the rehab program. Others have described effective swimmer specific strengthening and stretching programs that address strength and tissue length imbalances commonly found among swimmers. ${ }^{9,15}$ The aim of this commentary is to provide a brief overview of a strengthening and stretching program followed by a more intensive discussion of the NMES and taping protocols. Table 3 provides an overview of the strengthening and stretching program which includes scapular strengthening, shoulder neuromuscular re-education, rotator cuff strengthening, core strengthening and interventions to address forward head and rounded shoulder posture. Manual techniques and stretching are used to address posterior shoulder tightness, pectoralis minor/major and latissimus dorsi tightness. Phase 1 scapular strengthening begins with resisted retraction in neutral and manually resisted exercises for the scapula. Patients are progressed to prone T's, Y's, and 'field goals' (horizontal abduction with external rotation) in Phase 2 as irritability of symptoms diminishes and these higher demand exercises can be performed without pain. The Phase 2 exercises display high EMG activity of the middle trapezius, lower trapezius, infraspinatus, teres major and supraspinatus. ${ }^{27}$ They are incorporated into the program to counteract the muscle imbalances in swimmers that occur due to repetitive contraction of the pectorals and internal rotators during the swimming strokes. ${ }^{28}$ Using the same guideline, rotator cuff strengthening similarly begins in neutral in Phase 1 and progresses to greater angles of elevation in Phase $2 .{ }^{29}$

\section{BACKGROUND AND PROTOCOL FOR NEUROMUSCULAR ELECTRICAL STIMULATION}

Muscle weakness is a common finding in patients with shoulder injuries and studies support scapular muscle and posterior rotator cuff strengthening in the rehabilitation of shoulder pain among competitive swimmers. ${ }^{9,15}$ Loss of force production can result from muscle atrophy, fatigue, tendon tears, and voluntary activation failure (VAF). Weakness and VAF of the infraspinatus have been documented in healthy individuals with experimentally induced shoulder pain and shoulder fatigue. ${ }^{30,31}$ The addition of neuromuscular electrical stimulation (NMES) to the quadriceps muscle following knee surgery, after which VAF is a source of weakness, results in faster gains in strength and function when compared to traditional strengthening alone. ${ }^{32-34}$ Volitional muscle contractions sequentially recruit smaller motor units and Type 1 fibers within a muscle followed by large motor units and Type 2 fibers responsible for greater force production if needed. Application of NMES results in proportionally greater recruitment of large motor units at lower force levels than volitional contractions alone. 35 Therefore, it is likely that the mechanisms responsible for faster strength gains with NMES compared to volitional strengthening alone include direct recruitment of inhibited motor units and greater recruitment of Type 2 fibers than with voluntary contractions alone, resulting in greater force production. ${ }^{32}$ Accordingly, it is reasonable to suggest that clinicians may use NMES, as the protocol proposes, to more efficiently improve shoulder strength versus use of traditional strengthening alone.

In addition to the peripheral strengthening effects of NMES described above, there is evidence that changes in cerebral cortex function with NMES can enhance motor control. ${ }^{36,37}$ Cuesta-Gómez et $\mathrm{al}^{38}$ found that stimulation of the interscapular musculature, deltoid, triceps, and wrist extensors with a reaching task resulted in improved performance of the task, by increasing active shoulder flexion and elbow extension range of motion compared to use of placebo stimulation. This study did not include any measure of cerebral cortex function; however, other researchers found that cerebral cortex efficiency improved during motor tasks following a short application of NMES with volitional activity in the upper extremity. This beneficial cerebral cortex adaptation shows the potential to sustain improvements in neuroplasticity and motor control with NMES. ${ }^{36}$ Another study of 25 healthy subjects found that NMES with voluntary movement of the stimulated muscles increased cortical excitability to a greater extent than voluntary movement alone or NMES alone. ${ }^{37}$ This suggests that NMES may be used simultaneously with a desired motor task to prompt greater neuroplasticity than voluntary movement alone, leading to greater improvements in motor control. Use of NMES concurrently with a desired movement may be indicated when a primary treatment goal is to improve motor control. Therefore, the protocol for NMES contains guidance to address motor control deficits of the shoulder, when found, to stimulate neuroplasticity and improve neuromuscular control using the principles discussed in the above literature. It is important to address altered neuromuscular 
control to restore optimal biomechanics at the shoulder joint. Specifically, previous work supports promoting optimal scapular biomechanics for improving strength via enhanced length-tension relationships of the deltoid and other muscles which assist with shoulder elevation. ${ }^{39,40}$ It may also provide a more stable proximal fixation for these muscles and encourage erect thoracic posture while facilitating scapular posterior tilting and upward rotation. ${ }^{41}$

Favorable changes in glenohumeral biomechanics have also been described with application of NMES to the lower trapezius and serratus anterior. ${ }^{42}$ Researchers applied NMES simultaneously to these muscles and demonstrated increased acromiohumeral distance in healthy young adults. ${ }^{42}$ Electrodes were placed over the lower trapezius muscle belly between the inferior angle of the scapula and the seventh thoracic spinous process. For the serratus anterior muscle, electrodes were placed at the intersection of the sixth rib and the midaxillary line. These findings provide evidence for a biomechanical mechanism whereby NMES may reduce subacromial pain by increasing the subacromial space. However, this study only used NMES in a static, nonfunctional position among healthy participants. To the authors' knowledge, no studies exist on the application of NMES for neuromuscular re-education following shoulder injury in swimmers. The following section will present a protocol for NMES as an adjunct to traditional interventions for use in the treatment of shoulder pain in competitive swimmers.

The protocol (Table 4) includes applications of NMES for strengthening purposes and motor control, respectively. Phase 1 of the protocol begins with NMES applied to the middle and lower trapezius muscles with an isometric retraction contraction in a non-provocative position for those with high irritability. Once patients are pain-free with active horizontal abduction at 90 or 135 degrees of flexion in prone and weakness continues to be a primary concern, they are advanced to Phase $2 \mathrm{a}$. This phase progresses to isotonic strengthening in more functional positions for swimmers as these positions are required for the recovery phase of the swimming stroke. If strength has improved in Phase 1 and/or $2 \mathrm{a}$, but pain is still present with arm elevation, the authors perform symptom alteration tests to determine if the swimmer may have impairments in motor control. If pain with active shoulder elevation is significantly reduced or abolished with the modified scapular assistance test and/ or if the swimmer has a positive Jobe empty can test in which pain is reduced or abolished with the scapula reposition test, the swimmer is advanced to Phase $2 b$. In Phase $2 b$ NMES is used in conjunction with a specific task such as active shoulder elevation to improve motor control with this movement. If pain is reduced or eliminated or if active motion is improved with application of NMES in this manner, the authors consider this to indicate that impaired motor control is a contributing factor to the patient's pain. In the authors' clinical practice this finding suggests the clinician should proceed with use of NMES to the serratus anterior and mid/lower trapezius until the patient achieves pain-free active movement with carryover after NMES is removed. Carryover may occur rapidly or make take several sessions. If a desirable response is achieved with a simple task such as arm elevation, it is advised to progress to higher level ac- tivities such as performing resisted swimming strokes on a cable machine with light resistance. If a plateau is reached, NMES is discontinued and the patient is re-assessed to determine if other interventions are warranted.

\section{BACKGROUND AND IMPLEMENTATION OF TAPING}

Kinesiology and/or rigid taping are widely used techniques in the rehabilitation of shoulder injuries. ${ }^{43}$ There is an abundance of literature of varying quality on the use of taping as an adjunct to other physical therapy interventions; yet its effects remain inconclusive largely due to a lack of randomized placebo-controlled studies. ${ }^{43}$ Studies that demonstrate a positive effect on shoulder pain and function with taping propose that the mechanisms underlying these changes include: improved scapular positioning and enhancement of scapular kinematics, ${ }^{44,45}$ inhibition and/or facilitation of peri-scapular musculature, ${ }^{46-48}$ and improved shoulder joint proprioception and kinesthetic awareness/neuromuscular control. ${ }^{47}$ These mechanisms are relevant to the current topic given the previously discussed risk factors for shoulder pain among swimmers and the common impairments with which swimmers present. In this respect, taping may be a helpful adjunct to other physical therapy interventions for treating shoulder pain in swimmers. However, the inconclusive nature of the literature suggests caution is warranted with the use of tape in clinical practice. The authors therefore often perform a trial of taping and continue to use it only if there is an immediate improvement in pain or function.

In clinical practice, the authors primarily utilize a taping technique that mimics the scapula reposition test if this test is positive for pain reduction and the patient is unable to elevate their $\operatorname{arm}(\mathrm{s})$ or swim without pain. It is similar to the posterior scapular tilt technique outlined by Bdawai et $\mathrm{al}^{49}$ with some modification (Table 3). The tape is anchored, beginning at the anterior shoulder, inferior to the coracoid process and pull the tape over the upper trapezius muscle belly and continue posteriorly in an inferior and medial direction, covering the inferior angle of the scapula and crossing over the spine. This is performed bilaterally for symmetry. Clinicians may try kinesiology tape initially and if pain is abolished with active shoulder elevation and/or swimming strokes, may continue to use kinesiology tape. However, if kinesiology tape provides inadequate pain relief, rigid tape is recommended for greater support during daily activities only as rigid tape is too restrictive to be used while swimming. If no benefit is achieved with either technique, the rehabilitation process is continued as outlined above without using tape as an adjunct to treatment.

\section{CASE EXAMPLE}

\section{PATIENT HISTORY}

PK was a 15-year-old competitive swimmer, ranked in the top 25 in the country for his event with a goal of competing in college on scholarship. PK and his mother consented to data concerning his case being submitted for publication. He was referred to physical therapy with right shoulder pain 


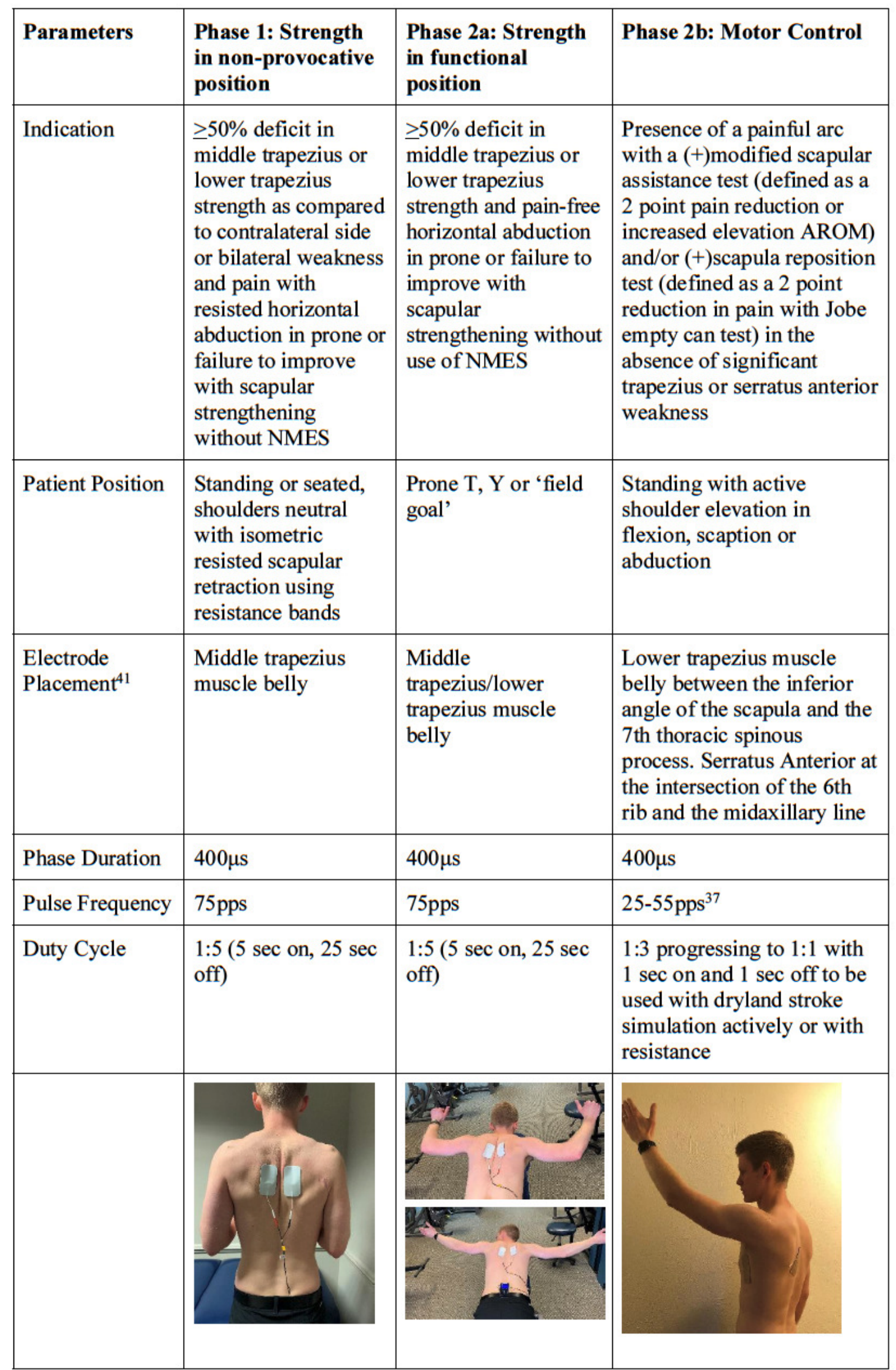

Table 4: Neuromuscular Electrical Stimulation (NMES)

that had been present for two months. Prior to experiencing shoulder pain, he had competed at nationals for the 200-yard backstroke, 100-yard freestyle and 100-yard breaststroke. His training regimen consisted of swimming 
Table 5: Comparison of outcomes at initial evaluation, progress evaluation and discharge

\begin{tabular}{|c|c|c|c|}
\hline Measure & Evaluation & $\begin{array}{l}\text { Progress } \\
\text { Evaluation } \\
\text { (Week 4) }\end{array}$ & $\begin{array}{l}\text { Discharge } \\
\text { Evaluation } \\
\text { (Week 8) }\end{array}$ \\
\hline \multicolumn{4}{|c|}{ Outcome Measures } \\
\hline NPRS (0-10) & $\begin{array}{l}4 \text { at present, } 8 \\
\text { at worst while } \\
\text { swimming }\end{array}$ & $\begin{array}{l}0 \text { at present, } 3 \\
\text { at worst while } \\
\text { swimming }\end{array}$ & $\begin{array}{l}0 \text { at } \\
\text { present, } 0 \\
\text { at worst }\end{array}$ \\
\hline Quick DASH & 29.5 & 9.1 & 0 \\
\hline \multicolumn{4}{|c|}{ Shoulder Range of Motion (degrees) } \\
\hline Active flexion & R 162* L 178 & R 179 & R 179 \\
\hline Active abduction & R 155* L 170 & R 170 & $\mathrm{R} 170$ \\
\hline Passive flexion & R 162* L 179 & R 180 & $\mathrm{R} 180$ \\
\hline Passive abduction & R 155* L 190 & $\mathrm{R} 190$ & $\mathrm{R} 190$ \\
\hline Passive external rotation & R 80* L 95 & R 95 & R 95 \\
\hline Passive internal rotation & $\mathrm{R} 20 \mathrm{~L} 25$ & R 31 & R 31 \\
\hline \multicolumn{4}{|c|}{ Strength [kg of force as measured by MicroFet 2 hand-held dynamometer (Hoggan Scientific, Salt Lake City, UT)] } \\
\hline Flexion at 90 & R 8.1* L 16.3 & R 13.6 & R 15.9 \\
\hline Abduction neutral & R $12.7^{*} \mathrm{~L} 16.3$ & $\mathrm{R} 24.1$ & R 25.4 \\
\hline External rotation prone & R 7.3* L 16.3 & R 11.8 & R 12.7 \\
\hline Internal rotation prone & R 9.1* L 17.3 & R 15.4 & R 18.2 \\
\hline Middle trapezius prone & R 4.5 L 5.4 & R unknown & R 5.4 \\
\hline Lower Trapezius prone & R $3.6^{*} \mathrm{~L} 5.0$ & R unknown & R 5.4 \\
\hline $\begin{array}{l}\text { Posterior shoulder endurance test: isometric hold with } 3 \mathrm{lb} \text { weight at } \\
145^{\circ} \text { horizontal abduction with thumb up (shoulder external } \\
\text { rotation) in prone }\end{array}$ & $\begin{array}{l}\text { R 10-sec L 35- } \\
\text { sec }\end{array}$ & R 57-sec & $\begin{array}{l}\text { R 71-sec L } \\
68-\sec \end{array}$ \\
\hline
\end{tabular}

* indicates pain provoked with movement or test

an average of 5000 meters per practice six days a week. He did not have an accompanying dry land program. PK initially experienced pain at the superior aspect of the right shoulder while doing backstroke which progressively worsened until all strokes were painful. PK had been limited to kicking drills with a kickboard for two months as recommended by his coach. An MRI during that time revealed small anterior and posterior labral tears. PK tried a course of physical therapy at another clinic for one month which reportedly consisted of band exercises, stretches and interferential E-stim. Due to lack of progress with this program, PK was referred to the authors' clinic to see an outpatient orthopedic physical therapist who specializes in treating swimmers.

\section{EXAMINATION}

PK's evaluation was consistent with the MRI findings of labral tears $[(+)$ dynamic shear test, and $(+)$ crank test] in addition to presenting with signs of subacromial pain syndrome $[(+)$ empty can test, $(+)$ Hawkins-Kennedy test, and $(+)$ painful arc] and anterior shoulder instability $[(+)$ anterior apprehension with $(+)$ relocation test]. He also had positive scapula reposition and modified scapular assistance tests which may be indicative of impairments in scapular contribution to shoulder elevation. Pectoralis minor, latis- simi dorsi and posterior shoulder tightness were also found. PK had reduced shoulder active and passive range of motion with empty end-feels. He had reduced glenohumeral and scapulothoracic strength in all planes compared to the contralateral shoulder (Table 5). PK also reported pain with activities of daily living including lifting dishes into upper cabinets, reaching behind his back to dress and bathe, and sitting to type and write for school.

\section{INTERVENTION AND OUTCOMES}

PK was seen at an outpatient clinic for approximately 60-minute sessions, two times a week for eight weeks and was team-treated by the authors of this paper. Table 6 outlines each week of PK's treatment, including his subjective report, important interventions that were added, and upgrades made to his home exercise program. For the purposes of this commentary, these categories are included for only the first five weeks of his treatment as PK primarily made progressions in volume and resistance for the interventions outlined over the final three weeks. At PK's first visit, he was advised to discontinue kicking with a kickboard overhead, a decision informed by McMaster et $\mathrm{al}^{6}$ who found that use of a kickboard increased shoulder symptoms in a group of swimmers with shoulder pain. Manual therapy techniques to improve soft tissue mobility and facilitate 
Table 6: Example case progression over the course of care*

\begin{tabular}{|c|c|c|}
\hline Subjective & Interventions Added & $\begin{array}{l}\text { Home Exercise \& } \\
\text { Swimming Progressions }\end{array}$ \\
\hline \multicolumn{3}{|c|}{ Visit 1-2 (Week 1) } \\
\hline $\begin{array}{l}\text { - Unable to stroke, only performing kicking } \\
\text { drills }\end{array}$ & $\begin{array}{l}\text { - NMES Phase } 1 \\
\text { - Scapula reposition taping } \\
\text { - Scapular mobilizations and manually resisted exercise, } \\
\text { rhythmic stabilization drills, instrument assisted soft } \\
\text { - } \text { tissue mobilization to posterior shoulder } \\
\text { - Resisted shoulder ER, IR, extension } \\
\text { - Pec minor stretch } \\
\text { - Prone T's and 'field goal' } \\
\text { - Core strengthening }\end{array}$ & $\begin{array}{l}\text { Scapula retraction, re- } \\
\text { sisted shoulder ER, IR \& } \\
\text { extension with elastic } \\
\text { band }\end{array}$ \\
\hline \multicolumn{3}{|c|}{ Visit 3-4 (Week 2) } \\
\hline $\begin{array}{l}\text { - No pain with swimming progressions with } \\
\text { fins and SRT tape. } \\
\text { - Carrying backpack for school still painful. }\end{array}$ & $\begin{array}{l}\text { - Instructed parent in scapula reposition taping tech- } \\
\text { nique to perform prior to swim practice } \\
\text { - NMES Phase 2a } \\
\text { - Reverse step up with bilateral ER } \\
\text { - Bilateral shoulder extension \& squat row } \\
\text { - Prone swimmers on swiss ball } \\
\text { - Modified sleeper stretch } \\
\text { - Latissimi stretch }\end{array}$ & $\begin{array}{l}\text { - } \quad \text { Prone T's and Y's } \\
\text { - } \text { Modified sleeper stretch } \\
\text { - } \quad \text { Latissimi stretch } \\
\text { - } \quad \text { Pec minor stretch }\end{array}$ \\
\hline \multicolumn{3}{|c|}{ Visit 5-6 (Week 3) } \\
\hline $\begin{array}{l}\text { - No pain with swimming progression early } \\
\text { in the week } \\
\text { - Pain with progression to no fins with par- } \\
\text { ent taping }\end{array}$ & $\begin{array}{l}\text { - Reviewed taping technique with parent } \\
\text { - Resisted breaststroke and freestyle at cable column } \\
\text { with number of strokes comparable to strokes com- } \\
\text { pleted in 50-yard swim }\end{array}$ & - Maintained \\
\hline \multicolumn{3}{|c|}{ Visit 7-8 (Week 4) } \\
\hline $\begin{array}{l}\text { - No pain with swimming progressions and } \\
\text { no pain at swim meet }\end{array}$ & $\begin{array}{l}\text { - } \text { Progressed to } 90^{\circ} \text { abduction for resisted ER \& IR with } \\
\text { - } \text { single leg stance } \\
\text { - } \text { Plank with serratus plus maneuver } \\
\text { - } \text { Advanced proprioceptive training } \\
\text { - } \text { Lawnmowed core strengthening } \\
\text { - } \text { High plank weight shifts on BOSU }\end{array}$ & $\begin{array}{l}\text { - Progressed to } 90^{\circ} \text { ab- } \\
\text { duction for resisted ER \& } \\
\text { IR with single leg stance }\end{array}$ \\
\hline \multicolumn{3}{|c|}{ Visit 9-10 (Week 5) } \\
\hline $\begin{array}{l}\text { - No pain with swimming progressions, oc- } \\
\text { casional pain with sitting at school early in } \\
\text { the week, no pain with other ADLs }\end{array}$ & $\begin{array}{l}\text { - Added lower extremity strengthening: Plyometric leg } \\
\text { press, resisted standing 3-way hip exercise (hip flexion, } \\
\text { abduction and extension) }\end{array}$ & - Maintained \\
\hline
\end{tabular}

*Patient was instructed in progressions in swimming yardage, intensity and frequency beginning with freestyle stroke using previously described soreness rules and progression guidelines based on the principles described by Spigelman et $\mathrm{al}^{2}$

muscular control, scapular stability and strength were initiated at PK's first visit. These were followed with targeted stretches and strengthening exercises for the scapular retractors, rotator cuff and core. These interventions were monitored and progressed as indicated to maintain appropriate volume and intensity throughout the course of PK's care and are presented in Table 6.

Table 6 includes the interventions that are the primary focus of this paper in bold which include the NMES protocol and taping interventions. Phase 1 of the NMES protocol (Table 4) was initiated during PK's first visit. By week 2, PK no longer had pain with resisted prone horizontal abduction, yet strength deficits persisted. PK progressed to Phase $2 \mathrm{a}$ of the protocol to continue strengthening in a functional position for swimming until PK's middle and lower trapez- ius strength were symmetrical bilaterally.

In week 1 of PK's physical therapy program, scapula reposition taping was performed (Table 3) which was warranted by the findings of positive scapula reposition and modified scapular assistance tests. Pain relief was achieved with kinesiology tape that PK reported was maintained with the swimming progressions he was instructed to perform between weeks 1 and 2 of treatment. Once PK was painfree with a reasonable training volume accounting for his specific swim events, his volume was progressed without scapular taping.

Throughout his rehabilitation program, PK was instructed in progressions in swimming volume, intensity and frequency using previously described soreness rules and progression guidelines based on the principles described by 
Spigelman et $\mathrm{al}^{2}$ and Hamman. ${ }^{1}$ The authors also followed the National Athletic Trainer's Association guideline recommending that youth athletes should progress distance or load in their specific sport by no more than $10 \%$ each week. ${ }^{14}$ Briefly, PK's in water program was initiated with only the freestyle stroke, using scapular reposition taping (Table 3 ) and long blade swim fins. Zamparo et $\mathrm{al}^{50}$ found that the energy cost swimming with fins is $40 \%$ less than swimming without them. Given Morouço et al's ${ }^{51}$ finding that the arms contribute $70.3 \%$ of propulsion for male swimmers, the use of fins can significantly reduce the shoulder load. PK initially began swimming a total of 800 meters/practice every other day with $75 \%$ of the distance swum with fins. Swimming volume was advanced approximately $10 \%$ per week. Once PK was able to perform 1200 meters of freestyle with use of fins and taping, he was instructed to perform $50 \%$ of his swimming volume without fins. Over the next 6 weeks, use of fins was gradually reduced and the swimming distance was increased until PK was able to swim a full practice without fins.

\section{CONCLUSION}

Shoulder pain is common among swimmers and can be attributed to a variety of risk factors including training errors and physical impairments. In-pool return to swim protocols have been described previously for swimmers who have been deactivated from swimming due to injury and/or who have full rotator cuff and periscapular muscle strength. However, clinicians are often left without clear guidance for treating swimmers with shoulder pain and physical impairments who continue in-pool practice. The authors have found the combination of dryland and in water training modifications as well as the use of NMES and taping to supplement a strengthening and stretching program has facilitated return of competitive swimmers to pre-injury levels. However, there are limitations to the protocol presented and the authors cannot conclude that this program is more effective than a traditional physical therapy program would be without the addition of NMES, taping, and training modifications. Therefore, further research is needed and welcomed to compare the efficacy of this and other protocols to determine optimal methods for managing shoulder pain in competitive swimmers.

\section{CONFLICTS OF INTEREST}

None

Submitted: February 06, 2020 CDT, Accepted: October 10, 2020 CDT 


\section{REFERENCES}

1. Hamman S. Considerations and return to swim protocol for the pediatric swimmer after nonoperative injury. Int J Sports Phys Ther.

2014;9(3):388-395.

2. Spigelman T, Sciascia A, Uhl T. Return to swimming protocol for competitive swimmers: a postoperative case study and fundamentals. Int J Sports Phys Ther. 2014;9(5):712-725. https://uknowledge.uk y.edu/rehabsci_facpub/40.

3. Tate A, Turner GN, Knab SE, Jorgensen C, Strittmatter A, Michener LA. Risk factors associated with shoulder pain and disability across the lifespan of competitive swimmers. J Athl Train. 2012;47(2):149-158. doi:10.4085/1062-6050-47.2.149

4. Montgomery SR, Chen NC, Rodeo SA. Arthroscopic capsular plication in the treatment of shoulder pain in competitive swimmers. HSS J. 2010;6(2):145-149. $\underline{\mathrm{d}}$ oi:10.1007/s11420-009-9153-4

5. Brushøj C, Bak K, Johannsen H, Faunø P. Swimmers' painful shoulder arthroscopic findings and return rate to sports. Scand J Med Sci Sport. June 2006. doi:10.1111/j.1600-0838.2006.00571.x

6. McMaster WC, Troup J. A survey of interfering shoulder pain in United States competitive swimmers. Am J Sports Med. 1993;21(1):67-70. doi:10.1177/03635 $\underline{4659302100112}$

7. Tate A, Harrington S, Buness M, Murray S, Trout C, Meisel C. Investigation of in-water and dry-land training programs for competitive swimmers in the United States. J Sport Rehabil. 2015;24(4):353-362. do i:10.1123/jsr.2014-0205

8. O'Donnell CJ, Bowen J, Fossati J. Identifying and managing shoulder pain in competitive swimmers. Phys Sportsmed. 2005;33(9):27-35. doi:10.3810/psm.2 $\underline{005.09 .195}$

9. Thigpen CA, Lynch SS, Mihalik JP, Prentice WE, Padua D. The effects of an exercise intervention on forward head and rounded shoulder postures in elite swimmers. Br J Sports Med. 2010;44(5):376-381. doi:1 $\underline{0.1136 / \text { bjsm.2009.066837 }}$

10. Zamparo P. Effects of age and gender on the propelling efficiency of the arm stroke. Eur J Appl Physiol. 2006. doi:10.1007/s00421-006-0133-9

11. Virag B, Hibberd EE, Oyama S, Padua DA, Myers JB. Prevalence of freestyle biomechanical errors in elite competitive swimmers. Sports Health. 2014;6(3):218-224. doi:10.1177/1941738114527056
12. Sein ML, Walton J, Linklater J, et al. Shoulder pain in elite swimmers: primarily due to swim-volumeinduced supraspinatus tendinopathy. Br J Sports Med. 2010;44(2):105-113. doi:10.1136/bjsm.2008.047282

13. McClure PW, Michener LA. Staged approach for rehabilitation classification: shoulder disorders (STAR-Shoulder). Phys Ther. 2015;95(5):791-800. do $\mathrm{i}: 10.2522 /$ ptj.20140156

14. Valovich McLeod TC, Decoster LC, Loud KJ, et al. National athletic trainers' association position statement: Prevention of pediatric overuse injuries. $J$ Athl Train. 2011;46(2):206-220. doi:10.4085/1062-605 $\underline{0-46.2 .206}$

15. Kluemper M, Uhl T, Hazelrigg H. Effect of stretching and strengthening shoulder muscles on forward shoulder posture in competitive swimmers. $J$ Sport Rehabil. 2006;15(1):58-70. doi:10.1123/isr.1 $\underline{5.1 .58}$

16. Myers JB, Oyama S, Wassinger CA, et al. Reliability, precision, accuracy, and validity of posterior shoulder tightness assessment in overhead athletes. Am J Sports Med. 2007;35(11):1922-1930. do i:10.1177/0363546507304142

17. Fieseler G, Laudner KG, Irlenbusch L, et al. Interand intrarater reliability of goniometry and hand held dynamometry for patients with subacromial impingement syndrome. J Exerc Rehabil. 2017;13(6):704-710. doi:10.12965/jer.1735110.555

18. Samosawala N, Vaishali K, Chakravarthy Kalyana B. Measurement of muscle strength with handheld dynamometer in Intensive Care Unit. Indian J Crit Care Med. 2016;20(1):21-26. doi:10.4103/0972-5229.1 $\underline{73683}$

19. Stark T, Walker B, Phillips JK, Fejer R, Beck R. Hand-held dynamometry correlation with the gold standard isokinetic dynamometry: A systematic review. Am J Phys Med Rehabil. 2011;3(5):472-479. do i:10.1016/i.pmrj.2010.10.025

20. Day JM, Bush H, Nitz AJ, Uhl TL. Scapular muscle performance in individuals with lateral epicondylalgia. J Orthop Sport Phys Ther. 2015. doi:1 $\underline{0.2519 / \text { iospt.2015.5290 }}$

21. Arab AM, Salavati M, Ebrahimi I, Mousavi ME. Sensitivity, specificity and predictive value of the clinical trunk muscle endurance tests in low back pain. Clin Rehabil. 2007;21(7):640-647. doi:10.1177/02 $\underline{69215507076353}$ 
22. Butowicz CM, Ebaugh DD, Noehren B, Silfies SP. Validation of two clinical measures of core stability. Int J Sports Phys Ther. 2016;11(1):15-23. http://www.n cbi.nlm.nih.gov/pubmed/26900496.

23. Tong TK, Wu S, Nie J. Sport-specific endurance plank test for evaluation of global core muscle function. Phys Ther Sport. 2014;15(1):58-63. doi:10.10 16/i.ptsp.2013.03.003

24. McGill SM, Childs A, Liebenson C. Endurance times for low back stabilization exercises: Clinical targets for testing and training from a normal database. Arch Phys Med Rehabil. 1999;80(8):941-944. doi:10.1016/S0003-9993(99)90087-4

25. Tate AR, McClure P, Kareha S, Irwin D. Effect of the scapula reposition test on shoulder impingement symptoms and elevation strength in overhead athletes. J Orthop Sports Phys Ther. 2008;38(1):4-11. d oi:10.2519/jospt.2008.2616

26. Rabin A, Irrgang JJ, Fitzgerald GK, Eubanks A. The intertester reliability of the scapular assistance test. $J$ Orthop Sport Phys Ther. 2006;36(9):653-660. doi:10.25 19/jospt.2006.2234

27. Reinold MM, Escamilla R, Wilk KE. Current concepts in the scientific and clinical rationale behind exercises for glenohumeral and scapulothoracic musculature. J Orthop Sports Phys Ther. 2009;39(2):105-117. doi:10.2519/jospt.2009.2835

28. Habechian FAP, Van Malderen K, Camargo PR, Cools AM. Changes in shoulder girdle strength in 3 consecutive years in elite adolescent swimmers: a longitudinal cohort study. Brazilian J Phys Ther. 2018;22(3):238-247. doi:10.1016/j.bjpt.2018.01.001

29. Tate AR, McClure PW, Young IA, Salvatori R, Michener LA. Comprehensive impairment-based exercise and manual therapy intervention for patients with subacromial impingement syndrome: A case series. J Orthop Sport Phys Ther. 2010;40(8):474-493. doi:10.2519/jospt.2010.3223

30. Stackhouse SK, Stapleton MR, Wagner DA, McClure PW. Voluntary activation of the infraspinatus muscle in nonfatigued and fatigued states. J Shoulder Elb Surg. 2010;19(2):224-229. doi:1 0.1016/j.jse.2009.07.006

31. Stackhouse SK, Eisennagel A, Eisennagel J, Lenker H, Sweitzer BA, McClure PW. Experimental pain inhibits infraspinatus activation during isometric external rotation. J Shoulder Elb Surg. 2013;22(4):478-484. doi:10.1016/j.jse.2012.05.037
32. Palmieri-Smith RM, Thomas AC, Wojtys EM. Maximizing quadriceps strength after ACL reconstruction. Clin Sports Med. 2008;27(3):405-424. doi:10.1016/j.csm.2008.02.001

33. Fitzgerald GK, Piva SR, Irrgang JJ. A modified neuromuscular electrical stimulation protocol for quadriceps strength training following anterior cruciate ligament reconstruction. J Orthop Sports Phys Ther. 2003;33(9):492-501. doi:10.2519/jospt.2003.3 $\underline{3.9 .492}$

34. Stevens-Lapsley JE, Balter JE, Wolfe P, Eckhoff DG, Kohrt WM. Early neuromuscular electrical stimulation to improve quadriceps muscle strength after total knee arthroplasty: A randomized controlled trial. Phys Ther. 2012;92(2):210-226. doi:1 $\underline{0.2522 / \mathrm{ptj} .20110124}$

35. Binder-Macleod SA, Halden EE, Jungles KA. Effects of stimulation intensity on the physiological responses of human motor units. Med Sci Sports Exerc. $1995 ; 27(4): 556-564$.

36. Jang SH, Jang WH, Chang PH, et al. Cortical activation change induced by neuromuscular electrical stimulation during hand movements: A functional NIRS study. J Neuroeng Rehabil. 2014;11(1). doi:10.1186/1743-0003-11-29

37. Barsi GI, Popovic DB, Tarkka IM, Sinkjær T, Grey MJ. Cortical excitability changes following grasping exercise augmented with electrical stimulation. Exp Brain Res. 2008;191(1):57-66. doi:10.1007/s00221-00 8-1495-5

38. Cuesta-Gómez A, Molina-Rueda F, CarratalaTejada M, Imatz-Ojanguren E, Torricelli D, Miangolarra-Page JC. The use of functional electrical stimulation on the upper limb and interscapular muscles of patients with stroke for the improvement of reaching movements: A feasibility study. Front Neurol. 2017;8:1-9. doi:10.3389/fneur.2017.00186

39. Kibler W, McMullen J. Scapular dyskinesis and its relation to shoulder pain. J Am Acad Orthop Surg. 2003;11(2):142-151.

40. Lieber R, Bodine-Fowler S. Skeletal muscle mechanics: implications for rehabilitation. Phys Ther. 1993;73:844-856.

41. Kebaetse M, McClure P, Pratt NA. Thoracic position effect on shoulder range of motion strength, and three-dimensional scapular kinematics. Arch Phys Med Rehabil. 1999;80(8):945-950. doi:10.1016/S0 003-9993(99)90088-6 
42. Bdaiwi AH, Mackenzie TA, Herrington L, Horsley I, Cools AM. Acromiohumeral distance during neuromuscular electrical stimulation of the lower trapezius and serratus anterior muscles in healthy participants. J Athl Train. 2015;50(7):713-718. doi:1 0.4085/1062-6050-50.4.03

43. Saracoglu I, Emuk Y, Taspinar F. Does taping in addition to physiotherapy improve the outcomes in subacromial impingement syndrome? A systematic review. Physiother Theory Pract. 2018;34(4):251-263. $\underline{\mathrm{d}}$ oi:10.1080/09593985.2017.1400138

44. Shaheen AF, Villa C, Lee Y-NN, Bull AMJ, Alexander CM. Scapular taping alters kinematics in asymptomatic subjects. J Electromyogr Kinesiol. 2013;23(2):326-333. doi:10.1016/j.jelekin.2012.11.005

45. Hsu Y-HH, Chen W-YY, Lin H-CC, Wang WTJJ, Shih Y-FF. The effects of taping on scapular kinematics and muscle performance in baseball players with shoulder impingement syndrome. $J$ Electromyogr Kinesiol. 2009;19(6):1092-1099. doi:10.1 016/i.jelekin.2008.11.003

46. Selkowitz DM, Chaney C, Stuckey SJ, Vlad G. The effects of scapular taping on the surface electromyographic signal amplitude of shoulder girdle muscles during upper extremity elevation in individuals with suspected shoulder impingement syndrome. J Orthop Sport Phys Ther. 2007;37(11):694-702. doi:10.2519/jospt.2007.2467
47. Lin J, Hung C-J, Yang P-L. The effects of scapular taping on electromyographic muscle activity and proprioception feedback in healthy shoulders. $J$ Orthop Res. 2011;29(1):53-57. doi:10.1002/jor.21146

48. Morin GE, Tiberio D, Austin G. The effect of upper trapezius taping on electromyographic activity in the upper and middle trapezius region. J Sport Rehabil. 1997;6(4):309-318. doi:10.1123/jsr.6.4.309

49. Bdaiwi AH, Mackenzie TA, Herrington L, Horlsey I, Cools A. The effects of rigid scapular taping on acromiohumeral distance in healthy shoulders: An observational study. J Sport Rehabil.

2017;26(1):51-56. doi:10.1123/jsr.2015-0086

50. Zamparo P, Pendergast DR, Termin B, Minetti AE. How fins affect the economy and efficiency of human swimming. J Exp Biol. 2002;205(17):2665-2676.

51. Morouço PG, Marinho DA, Izquierdo M, Neiva H, Marques MC. Relative contribution of arms and legs in front crawl tethered swimming, according to gender. Biomed Res Int. 2015. doi:10.1155/2015/56320 $\underline{6}$ 


\section{SUPPLEMENTARY MATERIALS}

\section{Table 2}

Download: https://ijspt.scholasticahq.com/article/21234-a-novel-rehabilitation-program-using-neuromuscularelectrical-stimulation-nmes-and-taping-for-shoulder-pain-in-swimmers-a-protocol-and-case-example/attachment/ 53972.pdf

\section{Table 3}

Download: https://ijspt.scholasticahq.com/article/21234-a-novel-rehabilitation-program-using-neuromuscularelectrical-stimulation-nmes-and-taping-for-shoulder-pain-in-swimmers-a-protocol-and-case-example/attachment/ 54468.pdf 